\title{
Strategy for Improving Efficiency of Supply Chain Quality Management in Buyer-Supplier Dyads: The Suppliers' Perspective
}

\author{
Hyun Jung Kim, ${ }^{1}$ Jiyoon Son, ${ }^{2}$ and Soo Wook Kim ${ }^{2}$ \\ ${ }^{1}$ Department of Business Administration, Sangji Youngseo College, Gangwon-do 26339, Republic of Korea \\ ${ }^{2}$ College of Business Administration, Seoul National University, Seoul 08826, Republic of Korea \\ Correspondence should be addressed to Jiyoon Son; imangela@snu.ac.kr
}

Received 22 October 2015; Revised 12 January 2016; Accepted 21 January 2016

Academic Editor: Paulina Golinska

Copyright (c) 2016 Hyun Jung Kim et al. This is an open access article distributed under the Creative Commons Attribution License, which permits unrestricted use, distribution, and reproduction in any medium, provided the original work is properly cited.

\begin{abstract}
This study analyzes the efficiency of supply chain quality management (SCQM) by grouping buyers and suppliers and conducting an empirical analysis of aspects affecting SCQM efficiency from the supplier's perspective. Two stages of data analysis were conducted: (1) classify buyer and supplier efficiency by means of data envelopment analysis (DEA) and sort the data results into a $2 \times 2$ matrix and (2) conduct a statistical analysis to verify influential aspects. The results depict the average value of Group I to be higher than that of Group II, while the average value of Group IV was found to be much lower than that of Group III. In addition, specific aspects have a significant impact on certain groups: Groups I and II are affected by infrastructure, delivery of quality, talent development, and risk management in that order; Groups II and III are likewise influenced by risk management, talent development, and delivery of quality, whereas Groups III and IV are influenced by talent development, delivery of quality, and risk management in that order.
\end{abstract}

\section{Introduction}

Supply chain quality management (SCQM) involves delivering the best quality products or services to clients through collaborative quality management of the supply chain by its members, such as buyer and supplier [1-4]. According to Foster [2], SCQM is defined as a systems-based approach to performance improvement that leverages opportunities created by upstream and downstream linkages with suppliers and customers. In other words, to gain competitive advantage and improve business performance, enterprises must monitor their internal efficiency and simultaneously manage companies within their chain or network. Quality management is not only about finding and correcting manufacturing defects but also about achieving quality in the entire organization and its supply chain network, influencing companies within the network.

Early studies focused on the concept of SCQM by analyzing aspects affecting corporate performance or exploring literature ranging from traditional quality control to SCQM.
Subsequently, the research direction shifted to empirical studies verifying that SCQM improves business performance and yields greater supply chain efficiency $[2,4-6]$. However, most studies have focused on SCQM effects on corporate performance through the supply chain, and little research has been conducted on the role of members in improving supply chain efficiency. Robinson and Malhotra [7] argued that quality management (QM) should be included in supply chain studies; indeed, some scholars have addressed SCQM with supply chain efficiency. These studies considered complex relationships within the supply chain and identify strategies that minimize cost by maximizing synergies within the supply chain. The studies also showed that a qualitycontrolled performance of supply chain members improves overall enterprise efficiency [8-10].

However, most of these studies have limitations. First, only well-known enterprise data were used given the ease in their collection. Therefore, these studies are buyer-biased $[9,11,12]$. Further, there is limited research about the effects of suppliers on SCQM efficiency. Some studies have noted 
the efficiency of the supplier, but the studies still deal with the position of the buyer [13]. Buyer and supplier influence business performance differently because of the distinct roles they play within the supply chain. Hence, it is necessary to identify their positions in the supply chain and their practices. Additionally, although some studies emphasized the importance of buyer and supplier efficiency on the overall supply chain, research regarding the specific aspects influencing enterprise performance has been inadequate $[9,14,15]$.

We measure SCQM efficiency considering each buyer and supplier and analyze their effect on the supply chain by grouping buyer and supplier, thereby contributing to the existing researches by reflecting both buyer's and supplier's positions in SCQM efficiency. This study provides practical implications and strategic insights for practitioners through an empirical analysis of survey data from 52 buyers and 346 suppliers based on the Quality Collaboration Index for Supply Chain Management (QCI-SCM) conducted by the Korean Standards Association. We distinguish SCQM efficiency under three categories-infrastructure, process, and performance-to examine the specific aspects affecting enterprise performance.

This paper is organized as follows: Section 1 explores the research purpose; Section 2 reviews recent literature on SCQM, key aspects of SCQM, and efficiency of SCQM; Section 3 provides a description of the method, input and output selection, and data collection; Section 4 presents the analysis of results; and Section 5 summarizes our findings and describes theoretical and practical implications of study.

\section{Literature Review}

2.1. SCQM. For SCQM competence, all supply chain members should be improved; thus, collaboration between companies is required $[6,12]$. In early studies, the term "SCQM" was not used, although the concept of integrating total quality management (TQM) and supply chain management (SCM) was recognized by scholars. TQM emphasizes the firm's internal competency, such as continuous quality improvement and employee participation, whereas SCM focuses on external partnerships to ensure, for example, the timely delivery of related products or services [6]. Thus, the integration of TQM and SCM is inevitable to improve competitiveness and customer satisfaction. Foster [2] defined SCQM as a systemsbased approach to performance improvement that leverages opportunities created by upstream and downstream linkages with suppliers and customers.

Several scholars have developed and empirically verified the SCQM aspects to assess the SCQM performance. Sharma et al. [13] investigated product recall events over 20 years through literature and found nine major causes for recalls. Dos Reis et al. [14] compared the performance between traditional QM and SCQM on food supply chains. Through a compilation of existing studies, $\mathrm{Hu}$ et al. [15] developed six critical aspects of SCQM considering internal and external influence aspects. Zhao et al. [16] provided a conceptual model of SCQM by theoretical research and insisted that corporations must continuously enhance SCQM to meet customer and market demands for high-quality products. In sum, studies on SCQM have gradually extended the scope of their research from the exploration of the concept of SCQM to the concrete elucidation of the key aspects of SCQM.

2.2. Key Aspects of SCQM. Foster [2] insisted to explore the key aspects and their effects on firm's performance to enrich the research fields on SCQM. Since the academic word "SCQM" arose in 2000s by integrating "TQM" and "SCM," previous literature on SCQM is limited. Therefore, we expand the literature review area to TQM and SCM to derive key aspects of SCQM. The key aspects relating to SCQM that we focus on in this study are infrastructure and process such as delivery of quality, talent development, and risk management.

Proper infrastructure is the foundation for executing supply chain quality management. Leadership and organizational structure were highlighted as key aspects for SCQM by recent researches. Dubey et al. [17] tested the impacts of supplier relationship management and total quality management on environmental performance under leadership and showed that leadership positively impacts TQM implementation and supply chain partners. Yinan et al. [18] demonstrated that the flat structure of organization affects supply chain planning and corporate coordination, which, in turn, directly improve manufacturing capability. Kumar et al. [19] explored the critical success aspects for the implementation of supply chain management, verifying that organizational behaviors, such as culture, vision, and structure, broadly impact supply chain quality management.

Process is another key aspect of SCQM. It comprises various elements, but we review the three key aspects currently under academic scrutiny: delivery of quality, talent development, and risk management. Numerous recent studies have emphasized the significance of quality management to cater to consumers' diversified needs. Delivery of quality is sequentially organized in order of product development, approval of production, purchasing, production and examination, storage, and delivery. Wang et al. [20] studied the importance of supply chain quality management in product design, logistic process, and provider and mass production in service supply chain management operations. Furthermore, Halldorsson et al. [21] advocated that successful supply chains are reliant on the continuous development of customerfriendly products and management quality.

Some studies highlighted the importance of individual stages of delivery of quality, such as product development, purchasing, and storage and delivery. Oh et al. [22] insisted that supporting complicated new product development procedures is important for total production process and maintaining product quality and Tracey and Neuhaus [23] argued the importance of purchasing in collaborative new productprocess development. This role of purchasing illustrates the complex network of relationships embedded in the project. Dayhim et al. [24] asserted that managing storage and delivery are important for managing demand uncertainty and delivery of quality, demonstrating that optimized storage management can decrease the total cost and increase the quality.

Talent development process for employees can be a key factor for assessing the SCQM performance. The process 
constitutes a workforce with the necessary skills and experience to deliver the firm's products or services over time [25]. Closs et al. [26] suggested a training guide for sustainable supply chain management. For supplier training, buyers can consistently work with supplier to ensure proper knowledge of relationship expectations and product specification standards. For internal employees, the firm conducts companywide training programs to anticipate issues and enhance working experience. Consequently, improving the employees' talent and knowledge derives quality performance.

Several researchers have stressed on the importance of risk management in TQM and SCM [27, 28]. Foster [2] mentioned that early quality controls, such as ISO 9000:2000, have developed to manage the uncertainty of benefits, risk of bureaucracy, costs, and production failing. Giannakis and Papadopoulos [29] demonstrated that the risk management involves collaboration among supply chain partners through exchange of information to enable mutual risk management. Moreover, by assessing risk management, opportunities to support the management of supply chain activities, to communicate and share information in a reliable method, to reduce instances of information asymmetry across the supply chain, and correctly to identify events that have the potential to create disruptions in supply chain processes arise.

In sum, although most previous studies examined infrastructure, delivery of quality, talent development, and risk management as the key aspects of SCQM, none has yet examined such aspects comprehensively. By analyzing aspects that have a greater effect on performance, corporations must grasp which aspects must be managed more intensively from the perspective of operation management. In this context, empirical research that examines which aspects must be managed further during the performance of SCQM by analyzing the efficiency between the key aspects of SCQM and performance is necessary.

2.3. Efficiency of SCQM. Since resources are limited, companies cannot blindly invest in quality activities. Therefore, the efficient use of resources could be a strategy for improving business performance. Accordingly to this, several studies have investigated the efficiency of SCQM with data envelopment analysis (DEA). Lin et al. [6] discovered strategies to minimize costs by maximizing the synergies among the parties in the supply chain using DEA. Bayraktar et al. [30] also used DEA to compare the relative efficiencies of SCM and information system practices demonstrating that despite small investment, focusing on SCQM can improve performance. Preceding SCQM literature using DEA was limited to single-party data, such as buyers only. However, to verify the adequate efficiency of SCQM, both internal and external partners should be analyzed with data from both parties, such as buyers and suppliers. Therefore, we utilize both buyers and suppliers data for analysis to differentiate with other studies.

While several scholars insist on the importance of buyersupplier relationship, most existing studies on the efficiency of SCQM are biased toward the buyer's practice. Lewis and Sexton [31] suggested a network model through theoretical research and empirical analysis using buyers data. They
TABLE 1: Classification by buyer-supplier comparison.

\begin{tabular}{lcc}
\hline Construct & Efficient & Buyer \\
& & Others \\
\hline Supplier & I & \\
Efficient & III & II \\
Others & IV \\
\hline
\end{tabular}

assumed that inefficient subunits affect supply chain network inefficiency. Wang and Shu [8] investigated buyer's supply chain management policies to minimize total supply chain cost by determining target service levels. They claimed to have reduced production cost and inventory investment for the efficiency of SCQM. Alavi and Pouriani [32] developed an efficiency measure model by selecting optimized suppliers for buyers, showing that managing supply chain visibility and reliability is a key factor to increase the buyer's performance. Liang et al. [11] insisted that measuring the correlation between buyers and suppliers is needed to analyze the relationships and performances. However, the buyers' data were used for the analysis; therefore, it is difficult to adequately reflect the suppliers' performance.

In sum, QM must be performed efficiently due to corporations' limited resources, and studies that analyze the efficiency of SCQM by using DEA therefore have continued to be conducted. However, none yet explored the efficiency of SCQM from the perspective of suppliers despite its necessity. Consequently, to enhance the efficiency of the entire supply chain, it is a necessity to examine the efficiency of both buyers and suppliers.

\section{Research Methodology}

3.1. Method. As can be seen in Table 1, the objects of study were classified into $2 \times 2$ matrix in accordance with the efficiency of buyers and suppliers. Group I shows that both buyers and suppliers are efficient; Group II shows that the buyers are in the "others" category while the suppliers are efficient; Group III shows the opposite of Group II; and Group IV shows the opposite of Group I.

To compare the efficiency of SCQM, we conducted a twostage analysis of buyer and supplier efficiency. First, DEA is used to distinguish efficiency data as described above. Second, we use discriminant analysis to identify independent variables influencing the $2 \times 2$ matrix classification.

3.1.1. DEA. Efficiency is the ratio of company performance to its resources. High efficiency means achieving higher output with the same input or the same output with less input. DEA is a linear programming-based model by Charnes et al. [33]. For DEA, a nonparametric technique is used to measure the relative efficiency of decision making units (DMUs) with multiple inputs and outputs.

In a more precise form, $x_{i j}$ and $y_{r j}$ are the known inputs and outputs of $j$ th DMU and $v_{r}$ and $v_{i} \geq 0$ are the variable weights to be determined when solving this problem. It is 
represented in the equation, for optimization, and in the constraints:

$$
\begin{array}{ll}
\operatorname{Max} & h_{0}=\frac{\sum_{r=1}^{s} u_{r} y_{r 0}}{\sum_{i=1}^{m} v_{i} x_{i 0}} \\
\text { s.t. } & \frac{\sum_{r=1}^{s} u_{r} y_{r j}}{\sum_{i=1}^{m} v_{i} x_{i j}} \leq 1 ; \quad j=1, \ldots, n, \\
& v_{r}, v_{i} \geq 0 ; \quad r=1, \ldots, s ; i=1, \ldots, m .
\end{array}
$$

Consider, for instance, that the following definition from the field of engineering efficiency is the ratio of the actual amount of heat liberated in a given device to the maximum amount that could be liberated by the fuel. In symbols,

$$
E_{r}=\frac{y_{r}}{y_{R}}
$$

where $y_{r}$ is maximum heat that can be obtained from a given input of fuel and $y_{R}$ is heat obtained by the input being rated from the same fuel input.

The rating is relative to some maximum possibility so that $0 \leq E_{r} \leq 1$ always. Therefore, by (1), $E_{r}$ can be obtained, and for any given input amount $x$ substitution in (1) gives

$$
\begin{array}{ll}
\operatorname{Max} & h_{0}=\frac{u y_{0}}{u x_{0}} \\
\text { s.t. } & \frac{u y_{R}}{u x_{R}} \leq 1, \\
& \frac{u y_{r}}{u x_{r}} \leq 1, \\
u, v & \geq 0,
\end{array}
$$

where $r=0$ in the functional designates that the latter is being rated. Let $u^{*}$ and $v^{*}$ represent an optimal pair of values. Since $y_{R} \geq y_{r}$ and $x_{R}=x_{r}=x$, this implies $u^{*} y_{R}=v^{*} x_{R}$. Using $x_{0}=x$, the functional is equal to $y_{r} / y_{R}$ as required. The model above is an extended nonlinear programming. However, Charnes et al. [33] suggested that a complete theory for fractional programming problems can be replaced with its linear programming equivalent. For conceptual flexibility, consider the following inefficiency model:

$$
\begin{array}{ll}
\text { Min } & f_{0}=\frac{\sum_{i=1}^{m} v_{i} x_{i 0}}{\sum_{r=1}^{s} u_{r} y_{r 0}} \\
\text { s.t. } & \frac{\sum_{i=1}^{m} v_{i} x_{i j}}{\sum_{r=1}^{s} u_{r} y_{r j}} \geq 1 ; j=1, \ldots, n, \\
& v_{r}, v_{i} \geq 0 .
\end{array}
$$

Furthermore, replacing these nonconvex and nonlinear formulations with a linear programming problem has been proposed

$$
\begin{array}{ll}
\operatorname{Max} & z_{0} \\
\text { s.t. } & -\sum_{j=1}^{n} y_{r j} \lambda_{j}+y_{r 0} z_{0} \leq 0 ; \quad r=1, \ldots, s, \\
& \sum_{j=1}^{n} x_{i j} \lambda_{j} \leq 1 ; \quad i=1, \ldots, m, \\
& \lambda_{j} \geq 0 ; \quad j=1, \ldots, n .
\end{array}
$$

Because the above equation is an ordinary linear programming problem, it has a linear programming dual:

$$
\begin{array}{ll}
\text { Min } & g_{0}=\sum_{i=1}^{m} \omega_{i} x_{i 0} \\
\text { s.t. } & -\sum_{r=1}^{s} \mu_{r} y_{r j}+\sum_{i=1}^{m} \omega_{i} x_{i j} \geq 0, \\
& \sum_{r=1}^{s} \mu_{r} y_{r 0}=1, \\
& \mu_{r}, \omega_{i} \geq 0 .
\end{array}
$$

Because of the structure of (6), one may recognize that it is equivalent to a linear fractional programming problem. Utilizing the theory of linear factional programming with the transformation,

$$
\begin{aligned}
\omega_{i} & =t v_{i} ; \quad i=1, \ldots, m, \\
\mu_{r} & =t u_{r} ; \quad r=1, \ldots, s, \\
t^{-1} & =\sum_{r}^{s} u_{r} y_{r 0},
\end{aligned}
$$

which, with $t>0$, explicitly gives

$$
\begin{array}{ll}
\text { Min } & f_{0}=\frac{\sum_{i=1}^{m} v_{i} x_{i 0}}{\sum_{r=1}^{s} u_{r} y_{r 0}} \\
\text { s.t. } & \sum_{i=1}^{m} v_{i} x_{i j}-\sum_{r=1}^{s} u_{r} y_{r j} \geq 0 ; \quad j=1, \ldots, n, \\
& v_{r}, v_{i} \geq 0 .
\end{array}
$$

The equations above help understanding fundamentals of DEA. DEA is capable of identifying best practices that are too complex to be accurately identified through observation. It is an objective method because statistical assumptions are unnecessary. Assume that there are $n$ DMUs $\left(\mathrm{DMU}_{1}, \mathrm{DMU}_{2}, \ldots, \mathrm{DMU}_{n}\right)$ to be evaluated. Varying amounts of $m$ different inputs are consumed by each DMU to produce $s$ different outputs. The $\mathrm{DMU}_{j}$ consumes $m$ inputs 
$x_{i j}(i=1, \ldots, m)$ to produce $s$ outputs $y_{r j}(r=1, \ldots, s)$. In the following model, the vectors of input and output values of the current DMU under evaluation, $\mathrm{DMU}_{p}$, are represented by $x_{i p}(i=1, \ldots, m)$ and $y_{r p}(r=1, \ldots, s)$, respectively [34]. Charnes, Cooper, and Rhodes (CCR) model is defined as follows:

$$
\begin{array}{ll}
\operatorname{Max} & W_{p}=\sum_{r=1}^{s}\left(u_{r} y_{r p}\right) \\
\text { s.t. } & \sum_{i=1}^{m}\left(v_{i} x_{i p}\right)=1 \\
& \sum_{r=1}^{s}\left(u_{r} y_{r j}\right)-\sum_{i=1}^{m}\left(v_{i} x_{i j}\right) \leq 0, \quad \forall j \\
& u_{r}, v_{i} \geq 0, \quad \forall j, r .
\end{array}
$$

When measuring efficiency, DEA is classified into the input-oriented model and the output-oriented model in accordance with the orientation. The input-oriented model has input decreasing while maintaining output, whereas the output-oriented model increases output while maintaining input. In addition, DEA is classified into the CCR model and the BCC model in accordance with whether the production relationship between input and output is one of constant returns to scale (CRS) or variable returns to scale (VRS) [35]. The CCR model is the standard DEA model using the CRS, assuming that a $1 \%$ increase in input produces a $1 \%$ increase in output. In contrast, the BCC model accepts the VRS where a $1 \%$ increase in input could turn out to be more or less than a $1 \%$ increase in output.

The efficiency score is usually denoted by a number between 0 and 1 . An efficiency score of 1 for a DMU shows that it is efficient relative to other units. The BCC model compensates for the shortcomings of the CCR model by adding constraints. Consequently, it calculates a higher DMU score than the CCR model [36]. The BCC model is defined as follows:

$$
\begin{array}{ll}
\operatorname{Max} & W_{p}=\sum_{r=1}^{s}\left(u_{r} y_{r p}\right) \\
\text { s.t. } & \sum_{r=1}^{s}\left(u_{r} y_{r j}\right)-\sum_{i=1}^{m}\left(v_{i} x_{i j}\right) \leq 0, \quad \forall j \\
& u_{r}, v_{i} \geq 0, \quad \forall j, r .
\end{array}
$$

By comparing the DMU scores of the CCR and BCC models, we can derive scale efficiency. If both scores are efficient, then the scale is efficient. Conversely, if the BCC score is efficient but the CCR ratio is inefficient, then the scale is inefficient. Therefore, if scale efficiency is 1 , the DMU is in its optimal state, and if it is less than 1 , scale inefficiency exists. This scale profit can be estimated by the sum of lambda, which can be construed as follows: if the sum of lambda is 1 , then it is CRS; if it is less than 1 , then it is increasing returns to scale (IRS); and if it is more than 1 , it is decreasing returns to scale (DRS).
In this study, we apply the output-oriented CCR and BCC model, particularly when setting the $2 \times 2$ matrix by comparing buyer and supplier efficiency. The Frontier Analyst Professional program is used.

3.1.2. Discriminant Analysis. Discriminant analysis is a statistical technique used to predict a categorical dependent variable by several continuous or binary independent variables. According to the scope of the dependent variable, when the category of the dependent variable is two, it is a two-group discriminant analysis, and, when it is more than three, it is a multiple discriminant analysis. This analysis finds coefficients of independent variables that maximize differences in distribution between groups. It also derives the discriminant functions and linear combinations of independent variables. In case of discriminant analysis with data not satisfying multivariate normality as an independent variable, the discriminant function estimation is compromised, and logistic regression should be executed. If the dependent variable does not satisfy the assumption of identical variancecovariance matrices, then the observed value is concentrated in the larger variance-covariance matrices group.

The two discriminant function estimation methods are simultaneous and stepwise estimation. Simultaneous estimation calculates coefficients for all independent variables concurrently, whereas stepwise estimation computes variables' canonical correlations. After estimation of the dependent variable, the significance of the function's discriminant power is verified with Wilks' lambda and check value of $\chi^{2}$; overall fit of function is tested by checking hit ratio to identify the number of correctly classified variables compared with the total population. Even though discriminant power of the dependent variable is statistically significant, if the hit ratio is low, then the function's discriminant power is not good. In this study, simultaneous estimation is applied for multiple discriminant analysis, and the SPSS program is used.

3.2. Input and Output Selection. Input and output variables were derived from the QCI-SCM survey data, published annually by the Korean Standards Association to measure business efficiency. The index includes infrastructure, processes, and performance.

Infrastructure refers to a basic structure for efficient collaboration between buyer and supplier. Detailed elements are configured as the five elements of corporate culture, leadership, organizational structure, system, and budget. A cooperative corporate culture that enables active communication and human resource development is a long-term factor affecting quality performance $[17,37]$. Leadership is referred to in several studies as a variable that deeply affects organizational performance. There are various studies on the effects of managerial leadership on enterprise productivity and net sales $[2,3,38]$. The organizational structure refers to the resources of the company as a traditional quality measurement element, adopting it as an existing key variable from the time when supply chain efficiency was initially extended to supply chain quality management $[3,9]$. The system does not regard internal resources as individual aspects but rather 
TABLE 2: Descriptive statistics of input and output variables.

\begin{tabular}{|c|c|c|c|c|}
\hline \multirow{2}{*}{ Variable } & \multicolumn{2}{|c|}{ Buyer } & \multicolumn{2}{|c|}{ Supplier } \\
\hline & Mean & Standard deviation & Mean & Standard deviation \\
\hline \multicolumn{5}{|l|}{ Input } \\
\hline Infrastructure & 27.57 & 6.57 & 13.95 & 5.69 \\
\hline Delivery of quality & 59.61 & 14.26 & 79.55 & 25.14 \\
\hline Talent development & 20.11 & 6.45 & 12.29 & 5.88 \\
\hline Risk management & 22.06 & 8.32 & 8.49 & 5.64 \\
\hline Support & 39.31 & 11.26 & - & - \\
\hline Communication & 25.63 & 8.78 & - & - \\
\hline Evaluation & 29.42 & 8.26 & - & - \\
\hline Benefit sharing & 17.09 & 10.43 & - & - \\
\hline \multicolumn{5}{|l|}{ Output } \\
\hline Performance & 45.54 & 24.44 & 81.33 & 18.48 \\
\hline Sales per person & 38.28 & 27.17 & 14.77 & 20.14 \\
\hline
\end{tabular}

perceives the relationship between the aspects and considers their interconnectivity as variables which affect performance $[3,16]$. The last component, budget, is rarely mentioned as a factor affecting business performance; however, the budget for QM is an important factor for generating the TQM. Kuei and Madu [3] also mentioned the importance of cost and budget in QM research.

Further, SCQM is a collaborative process between buyer and supplier to improve quality of the final product and comprises seven processes: delivery of quality, talent development, risk management, support, communication, evaluation, and benefit sharing. Each process has subcriteria and each criterion was chosen by comprehensive quality management aspects mentioned in traditional quality practice and SCQM literature [2, 4]. A core process in SCQM is delivery of quality, whereas other processes have the tendency to compensate. Support, communication, evaluation, and benefit sharing are common processes that affect buyer and supplier interaction. These seven processes are noted as important variables to evaluate quality practice and supply chain efficiency by several scholars [2].

Finally, performance refers to business performance through cooperation between buyer and supplier and is used as an output variable in analysis. Performance criteria are achieved with traditional quality management and SCQM $[4,7,16]$. The seven buyer performance criteria not only measure production quality control practices but also can be scaled to include communication and employee training $[2,4,6,7]$. By contrast, supplier performance is measured using five performance criteria: quality, cost, productivity, safety-environmental, and ethical performance.

3.3. Data Collection. A distinguishing feature of this study is the use of data from a well-defined management survey annually developed by the Korean Standards Association since 2005. We use supply chain data collected after September 2008 from 52 buyers and 346 suppliers for Korean firms in various manufacturing industries. After eliminating responses with missing data, 48 buyers and 309 suppliers were analyzed.
Input and output data for analysis are as follows. For buyer, eight input variables and two output variables are used. For supplier, four input variables and two output variables are applied. Buyer's input variables are infrastructure, delivery of quality, talent development, risk management, support, communication, evaluation, and benefit sharing. The output variables are performance and sales per person. Supplier's input variables are infrastructure, delivery of quality, talent development, and risk management. The output variables are performance and sales per person. Descriptive statistics of the input and output variables are shown in Table 2.

\section{Results}

4.1. Results of DEA. The DEA results show that both buyers and suppliers-efficient are most common in Group I $(n=6)$, buyers-others and suppliers-efficient are most common in Group II $(n=13)$, buyers-efficient and suppliers-others are most common in Group III $(n=87)$, and both buyers and suppliers-others are most common in Group IV $(n=203)$.

The analyzed results for supplier efficiency are displayed in Table 3. We compare the mean values of group efficiency scores between the suppliers-efficient groups and suppliers-others groups to explore suppliers efficiency. For the suppliers-efficient groups (I, II), the BCC score shows 1 for both groups. Group I's efficiency average score is 1.00 (BCC) and 0.78 (CCR), whereas Group II's efficiency average score is 1.00 (BCC) and 0.74 (CCR); the CCR model shows a slightly higher average score for Group I. In terms of the supply chain condition, this indicates that the suppliers can execute more efficient SCQM when both the buyers and the suppliers are efficient.

Regarding the suppliers-others groups (III, IV), the efficiency average score for Group III is 0.75 (BCC) and 0.56 (CCR) while that for Group IV is 0.66 (BCC) and 0.35 (CCR). Group IV needs urgent improvement in SCQM efficiency, with $91.6 \%$ of DMU efficiency scores below 0.6 . If the supplier is included in others, then the supplier can execute SCQM more efficiently in the buyer-efficient case than in the buyerothers case. Considering buyers lead the supply chain in 
TABLE 3: Efficiency score.

\begin{tabular}{|c|c|c|c|c|c|c|}
\hline \multirow{2}{*}{ Group } & \multirow{2}{*}{ Number } & \multirow{2}{*}{ Efficiency score } & \multicolumn{2}{|c|}{ CCR model } & \multicolumn{2}{|c|}{ BCC model } \\
\hline & & & Number & Percentage & Number & Percentage \\
\hline \multirow{6}{*}{ I } & \multirow{6}{*}{6} & $E=1$ & 3 & $50.0 \%$ & 6 & $100.0 \%$ \\
\hline & & $0.9 \leq E<1$ & 0 & $0.0 \%$ & 0 & $0.0 \%$ \\
\hline & & $0.8 \leq E<0.9$ & 0 & $0.0 \%$ & 0 & $0.0 \%$ \\
\hline & & $0.7 \leq E<0.8$ & 0 & $0.0 \%$ & 0 & $0.0 \%$ \\
\hline & & $0.6 \leq E<0.7$ & 0 & $0.0 \%$ & 0 & $0.0 \%$ \\
\hline & & $E<0.6$ & 3 & $50.0 \%$ & 0 & $0.0 \%$ \\
\hline \multirow{6}{*}{ II } & \multirow{6}{*}{13} & $E=1$ & 9 & $69.2 \%$ & 13 & $100.0 \%$ \\
\hline & & $0.9 \leq E<1$ & 0 & $0.0 \%$ & 0 & $0.0 \%$ \\
\hline & & $0.8 \leq E<0.9$ & 0 & $0.0 \%$ & 0 & $0.0 \%$ \\
\hline & & $0.7 \leq E<0.8$ & 0 & $0.0 \%$ & 0 & $0.0 \%$ \\
\hline & & $0.6 \leq E<0.7$ & 1 & $7.7 \%$ & 0 & $0.0 \%$ \\
\hline & & $E<0.6$ & 3 & $23.1 \%$ & 0 & $0.0 \%$ \\
\hline \multirow{6}{*}{ III } & \multirow{6}{*}{87} & $E=1$ & 0 & $0.0 \%$ & 0 & $0.0 \%$ \\
\hline & & $0.9 \leq E<1$ & 1 & $1.1 \%$ & 12 & $13.8 \%$ \\
\hline & & $0.8 \leq E<0.9$ & 3 & $3.5 \%$ & 21 & $24.2 \%$ \\
\hline & & $0.7 \leq E<0.8$ & 4 & $4.6 \%$ & 22 & $25.3 \%$ \\
\hline & & $0.6 \leq E<0.7$ & 6 & $6.9 \%$ & 13 & $14.9 \%$ \\
\hline & & $E<0.6$ & 73 & $83.9 \%$ & 19 & $21.8 \%$ \\
\hline \multirow{6}{*}{ IV } & \multirow{6}{*}{203} & $E=1$ & 0 & $0.0 \%$ & 0 & $0.0 \%$ \\
\hline & & $0.9 \leq E<1$ & 0 & $0.0 \%$ & 22 & $10.8 \%$ \\
\hline & & $0.8 \leq E<0.9$ & 7 & $3.5 \%$ & 32 & $15.8 \%$ \\
\hline & & $0.7 \leq E<0.8$ & 7 & $3.5 \%$ & 65 & $32.0 \%$ \\
\hline & & $0.6 \leq E<0.7$ & 3 & $1.4 \%$ & 42 & $20.7 \%$ \\
\hline & & $E<0.6$ & 186 & $91.6 \%$ & 42 & $20.7 \%$ \\
\hline
\end{tabular}

TABLE 4: Results of discriminant analysis.

\begin{tabular}{|c|c|c|c|c|c|c|c|c|c|}
\hline \multirow{3}{*}{ Variable } & \multicolumn{9}{|c|}{ Linear discriminant function } \\
\hline & \multicolumn{3}{|c|}{1} & \multicolumn{3}{|c|}{2} & \multicolumn{3}{|c|}{3} \\
\hline & Coefficient & $\begin{array}{c}\text { Standardized } \\
\text { coefficient }\end{array}$ & $\begin{array}{l}\text { Structure } \\
\text { matrix }\end{array}$ & Coefficient & $\begin{array}{c}\text { Standardized } \\
\text { coefficient }\end{array}$ & $\begin{array}{l}\text { Structure } \\
\text { matrix }\end{array}$ & Coefficient & $\begin{array}{c}\text { Standardized } \\
\text { coefficient }\end{array}$ & $\begin{array}{l}\text { Structure } \\
\text { matrix }\end{array}$ \\
\hline (Constant) & -2.943 & & & 0.076 & & & 0.135 & & \\
\hline Infrastructure & 1.606 & 0.651 & 0.959 & -2.660 & -1.077 & -0.044 & -0.097 & -0.039 & -0.079 \\
\hline Delivery of quality & 1.185 & 0.377 & 0.901 & 0.161 & 0.051 & 0.335 & 1.788 & 0.569 & 0.383 \\
\hline Talent development & 0.335 & 0.158 & 0.755 & 1.051 & 0.496 & 0.420 & 2.824 & 1.333 & 0.503 \\
\hline Risk management & -0.199 & -0.132 & 0.629 & 1.690 & 1.121 & 0.670 & -1.092 & -0.724 & -0.307 \\
\hline Eigen value & & 0.164 & & & 0.126 & & & 0.102 & \\
\hline Explained variance & & 100 & & & 100 & & & 100 & \\
\hline Canonical correlation & & 0.446 & & & 0.358 & & & 0.240 & \\
\hline Wilks' lambda & & $0.915^{* * *}$ & & & $0.973^{* *}$ & & & $0.998^{*}$ & \\
\hline
\end{tabular}

${ }^{*} p<0.1,{ }^{* *} p<0.05$, and ${ }^{* * *} p<0.01$.

general, this may be because when buyers practice efficient SCQM suppliers with whom they engage in transactions are demanded to attain a certain level of efficiency in SCQM.

4.2. Results of Discriminant Analysis. By comparing buyer and supplier efficiency, we developed a $2 \times 2$ matrix and conducted DEA to derive efficiency scores. We used $2 \times$ 2 matrix groups as dependent variables for discriminant analysis and supplier's SCQM aspects such as infrastructure, delivery of quality, talent development, and risk management for independent variables.

According to the discriminant analysis results, since the number of groups is four, three discriminant functions were derived. As shown in Table 4, $p$ values were smaller than 0.1 for all discriminant functions. This means that, by using independent variables from the prior analysis, samples have been well divided into statistically significant groups. The second discriminant function describes the statistical 
TABLE 5: Results of classification.

\begin{tabular}{lccccc}
\hline $\begin{array}{l}\text { Actual affiliated } \\
\text { group }\end{array}$ & \multicolumn{5}{c}{ Predicted affiliated group } \\
\hline 1 & 2 & 2 & 3 & 4 & Total \\
\hline \multirow{2}{*}{2} & $(33.3 \%)$ & $(33.3 \%)$ & $(16.7 \%)$ & $(16.7 \%)$ & $(100.0 \%)$ \\
& 2 & 8 & 0 & 3 & 13 \\
3 & $(15.4 \%)$ & $(61.5 \%)$ & $(0.0 \%)$ & $(23.1 \%)$ & $(100.0 \%)$ \\
& 9 & 8 & 52 & 18 & 87 \\
4 & $(10.3 \%)$ & $(9.2 \%)$ & $(59.8 \%)$ & $(20.7 \%)$ & $(100.0 \%)$ \\
& 13 & 39 & 22 & 129 & 203 \\
& $(6.4 \%)$ & $(19.2 \%)$ & $(10.8 \%)$ & $(63.6 \%)$ & $(100.0 \%)$ \\
\hline
\end{tabular}

significance between groups after eliminating the impact factors of the first discriminant function. Likewise, the third discriminant function describes the statistical significance between groups after removing the impact factors of the second discriminant function.

When interpreting discriminant analysis results, discriminant power between independent variables can appear low because of multicollinearity; therefore, discriminant loading values of structure matrix were used, which means a correlation between variables and standardized canonical discriminant functions exists [39]. The first discriminant function Wilks' lambda is 0.915 , which is statistically significant at the 0.01 level. In general, if the absolute value of discriminant loading is more than 0.3 , it is considered statistically significant. Discriminant power is strong in the sequence of infrastructure (0.959), delivery of quality (0.901), talent development (0.755), and risk management (0.629). The second discriminant function, Wilks' lambda, is 0.973 and is statistically significant at 0.05 . Discriminant power is in the sequence of risk management (0.670), talent development $(0.420)$, and delivery of quality (0.335). The third discriminant function Wilks' lambda is 0.998 and is statistically significant at 0.1 , with discriminant power in the sequence of talent development (0.503), delivery of quality (0.383), and risk management $(-0.307)$. Between Groups I and II, the sequence of importance is infrastructure, delivery of quality, talent development, and risk management. Between Groups II and III, the sequence of importance is risk management, talent development, and delivery of quality. Between Groups III and IV, the sequence of importance is talent development, delivery of quality, and risk management.

Table 5 shows how well the classification predicts supplier SCQM efficiency. In this study, samples have correctly classified 191 of 309 companies, with an overall hit ratio of $61.8 \%$. Consequently, the classification of the respective efficiency of buyers and suppliers was confirmed to be highly accurate.

\section{Conclusion}

This study analyzes the efficiency of SCQM by grouping buyer and supplier data and conducting an empirical analysis of aspects affecting SCQM efficiency from the supplier's perspective. Two stages of data analysis were completed. The first stage separated buyer and supplier efficiency using DEA. In the second stage, $2 \times 2$ matrix was used to sort buyers and suppliers by efficiency and conduct statistical analyses. The four groups were as follows: Group I (both buyers and suppliers are efficient), Group II (buyers are "others" but suppliers are efficient), Group III (buyers are efficient but suppliers are "others"), and Group IV (both buyers and suppliers are "others"). The results show the efficiency average score of Group I to be higher than Group II and the efficiency average score of Group IV to be much lower than Group III. This result is consistent with the results of previous researches $[11,13]$. In addition, specific aspects have a significant impact on certain groups; for example, Groups I and II are affected in the sequence of infrastructure, delivery of quality, talent development, and risk management. Between Groups II and III, the sequence of importance is risk management, talent development, and delivery of quality. Groups III and IV are influenced by talent development, delivery of quality, and risk management in that order.

The theoretical implications of this paper are as follows. First, this study is significant because it takes into consideration the perspective of buyers as well in analyzing the efficiency of suppliers' SCQM by separately analyzing the efficiency of buyers and suppliers and then analyzing efficiency per the corporations with which transactions are executed. Previous researches in the SCQM efficiency mainly dealt with performance measurement from the buyer's or supplier's perspective. In particular, researches on the efficiency of SCQM have been conducted mainly from the perspective of buyers, who are considered the main beneficiaries in SCQM $[12,13]$. Second, this study also contributes to the broader literature on how key aspects of SCQM influence efficiency. Although the existing literature acknowledges the need to understand how buyer and supplier efficiency affect overall supply chain performance, little research has been conducted $[8,9]$. Our result confirms that managing SCQM aspects, such as infrastructure and processes, affects supplier efficiency.

When the practical implications of this study are examined, corporate executives can determine whether a firm needs to focus on certain aspects to improve SCQM efficiency based on the findings of this study. Managers should identify the firm's position within the supply chain and perceive the efficiency of partner firms in the business relationship. If the firm is a supplier, then it must set management priorities among infrastructure, delivery of quality, talent development, and risk management. For example, if the firm is efficient but the partner buyer is in the "others" category, the firm then needs to increase its own efficiency by managing its infrastructure, delivery of quality, talent development, and risk management in order and deliver efficiency indirectly to the buyer; hence, the relationship is improved such that both buyer and supplier are efficient.

This study has the following limitations. First, the objects of this study were classified into $2 \times 2$ matrix in accordance with the efficiency of buyers and suppliers. This classification can raise concerns about dichotomization of scale variables by giving less consideration to values in the middle. In further research, the classification can be more divided into small groups that can range over the various groups of efficiency. Second, our research is focused on the supplier's perspective, 
with less consideration of the buyer's position; however, an empirical analysis was conducted on both buyer and supplier data. Because 4-9 suppliers were matched to each buyer in the data used in this study, it was impossible to classify buyers clearly into each group by using $2 \times 2$ matrix through a comparison of buyers and suppliers in efficiency. Consequently, this study could not examine SCQM efficiency that, from the perspective of suppliers, took into consideration buyers' efficiency as well. Third, our sample was restricted to the data from the Korean Standards Association; therefore, our findings may not be generalized to all firms in the industry. We hope that, in future research, we will be able to examine SCQM efficiency that takes into consideration both buyers and suppliers, with corporations in diverse countries as the objects.

\section{Conflict of Interests}

The authors declare that there is no conflict of interests regarding the publication of this paper.

\section{References}

[1] B. B. Flynn and E. J. Flynn, "Synergies between supply chain management and quality management: emerging implications," International Journal of Production Research, vol. 43, no. 16, pp. 3421-3436, 2005.

[2] S. T. Foster, "Towards an understanding of supply chain quality management," Journal of Operations Management, vol. 26, no. 4, pp. 461-467, 2008.

[3] C. Kuei and C. N. Madu, "Identifying critical success factors for supply chain quality management (SCQM)," Asia Pacific Management Review, vol. 6, no. 4, pp. 409-423, 2001.

[4] H. Kaynak and J. L. Hartley, "A replication and extension of quality management into the supply chain," Journal of Operations Management, vol. 26, no. 4, pp. 468-489, 2008.

[5] A. C. L. Yeung, "Strategic supply management, quality initiatives, and organizational performance," Journal of Operations Management, vol. 26, no. 4, pp. 490-502, 2008.

[6] C. Lin, C.-H. Kuei, and K.-W. Chai, "Identifying critical enablers and pathways to high performance supply chain quality management," International Journal of Operations \& Production Management, vol. 33, no. 3, pp. 347-370, 2013.

[7] C. J. Robinson and M. K. Malhotra, "Defining the concept of supply chain quality management and its relevance to academic and industrial practice," International Journal of Production Economics, vol. 96, no. 3, pp. 315-337, 2005.

[8] J. Wang and Y.-F. Shu, "A possibilistic decision model for new product supply chain design," European Journal of Operational Research, vol. 177, no. 2, pp. 1044-1061, 2007.

[9] C. Lin, W. S. Chow, C. N. Madu, C.-H. Kuei, and P. Pei Yu, "A structural equation model of supply chain quality management and organizational performance," International Journal of Production Economics, vol. 96, no. 3, pp. 355-365, 2005.

[10] M. Perona and G. Miragliotta, "Complexity management and supply chain performance assessment. A field study and a conceptual framework," International Journal of Production Economics, vol. 90, no. 1, pp. 103-115, 2004.
[11] L. Liang, F. Yang, W. D. Cook, and J. Zhu, "DEA models for supply chain efficiency evaluation," Annals of Operations Research, vol. 145, pp. 35-49, 2006.

[12] A. Amirteimoori and L. Khoshandam, "A data envelopment analysis approach to supply chain efficiency," Advances in Decision Sciences, vol. 2011, Article ID 608324, 8 pages, 2011.

[13] A. Sharma, D. Garg, and A. Agarwal, "Product recall: supply chain quality issue?" International Journal of Intelligent Enterprise, vol. 2, no. 4, pp. 277-293, 2014.

[14] J. G. M. Dos Reis, S. T. Machado, P. L. O. C. Neto, R. Monteiro, and J. B. Sacomano, "Supply chain quality management in agribusiness: an approach of quality management systems in food supply chains," in Advances in Production Management Systems. Innovative and Knowledge-Based Production Management in a Global-Local World, vol. 440 of IFIP Advances in Information and Communication Technology, pp. 497-504, Springer, Berlin, Germany, 2014.

[15] H. Hu, B. Flynn, and X. Zhao, Global Supply Chain Quality Management: Product Recalls and Their Impact, CRC Press, Boca Raton, Fla, USA, 2014.

[16] J. Zhao, Y. Hu, and Y. Wang, "Supply chain quality management based on information asymmetry," International Journal of Sociology Study, vol. 3, no. 1, pp. 1-5, 2015.

[17] R. Dubey, A. Gunasekaran, and S. S. Ali, "Exploring the relationship between leadership, operational practices, institutional pressures and environmental performance: a framework for green supply chain," International Journal of Production Economics, vol. 160, pp. 120-132, 2015.

[18] Q. Yinan, M. Tang, and M. Zhang, "Mass customization in flat organization: the mediating role of supply chain planning and corporation coordination," Journal of Applied Research and Technology, vol. 12, no. 2, pp. 171-181, 2014.

[19] R. Kumar, R. K. Singh, and R. Shankar, "Critical success factors for implementation of supply chain management in Indian small and medium enterprises and their impact on performance," IIMB Management Review, vol. 27, no. 2, pp. 92 104,2015

[20] Y. Wang, S. W. Wallace, B. Shen, and T. Choi, "Service supply chain management: a review of operational models," European Journal of Operational Research, vol. 247, no. 3, pp. 685-698, 2015.

[21] A. Halldorsson, H. Kotzab, J. H. Mikkola, and T. Skjøtt-Larsen, "Complementary theories to supply chain management," Supply Chain Management, vol. 12, no. 4, pp. 284-296, 2007.

[22] J. Oh, S. Lee, and J. Yang, "A collaboration model for new product development through the integration of PLM and SCM in the electronics industry," Computers in Industry, vol. 73, pp. 82-92, 2015.

[23] M. Tracey and R. Neuhaus, "Purchasing's role in global new product-process development projects," Journal of Purchasing and Supply Management, vol. 19, no. 2, pp. 98-105, 2013.

[24] M. Dayhim, M. A. Jafari, and M. Mazurek, "Planning sustainable hydrogen supply chain infrastructure with uncertain demand," International Journal of Hydrogen Energy, vol. 39, no. 13, pp. 6789-6801, 2014.

[25] B. Colbert and E. Kurucz, "Three conceptions of triple bottom line business sustainability and the role for HRM," People and Strategy, vol. 30, no. 1, pp. 21-29, 2007.

[26] D. J. Closs, C. Speier, and N. Meacham, "Sustainability to support end-to-end value chains: the role of supply chain management," Journal of the Academy of Marketing Science, vol. 39, no. 1, pp. 101-116, 2011. 
[27] H. Gurnani, S. Ray, and Y. Wang, "Special issue of production and operations management: 'global supply chain risk management,' Production and Operations Management, vol. 20, no. 3, pp. 489-489, 2011.

[28] O. Tang, H. Matsukawa, and K. Nakashima, "Supply chain risk management," International Journal of Production Economics, vol. 139, no. 1, pp. 1-2, 2012.

[29] M. Giannakis and T. Papadopoulos, "Supply chain sustainability: a risk management approach," International Journal of Production Economics, vol. 171, pp. 455-470, 2016.

[30] E. Bayraktar, E. Tatoglu, A. Turkyilmaz, D. Delen, and S. Zaim, "Measuring the efficiency of customer satisfaction and loyalty for mobile phone brands with DEA," Expert Systems with Applications, vol. 39, no. 1, pp. 99-106, 2012.

[31] H. F. Lewis and T. R. Sexton, "Network DEA: efficiency analysis of organizations with complex internal structure," Computers \& Operations Research, vol. 31, no. 9, pp. 1365-1410, 2004.

[32] S. H. Alavi and M. Pouriani, "Research note: fuzzy supplier selection by use of weighted indices," International Journal of Management, Accounting and Economics, vol. 1, no. 2, pp. 125132, 2014.

[33] A. Charnes, W. W. Cooper, and E. Rhodes, "Measuring the efficiency of decision making units," European Journal of Operational Research, vol. 2, no. 6, pp. 429-444, 1978.

[34] M. Kumar, M. K. Tiwari, K. Y. Wong, K. Govindan, and C. T. Kuah, "Evaluating reverse supply chain efficiency: manufacturer's perspective," Mathematical Problems in Engineering, vol. 2014, Article ID 901914, 9 pages, 2014.

[35] R. D. Banker, A. Charnes, and W. W. Cooper, "Some models for estimating technical and scale inefficiencies in data envelopment analysis," Management Science, vol. 30, no. 9, pp. 10781092, 1984.

[36] R. D. C. Miranda, J. A. B. Montevechi, A. F. D. Silva, and F. A. S. Marins, "A new approach to reducing search space and increasing efficiency in simulation optimization problems via the fuzzy-DEA-BCC," Mathematical Problems in Engineering, vol. 2014, Article ID 450367, 15 pages, 2014.

[37] B. B. Flynn, R. G. Schroeder, and S. Sakakibara, "A framework for quality management research and an associated measurement instrument," Journal of Operations Management, vol. 11, no. 4, pp. 339-366, 1994.

[38] S. L. Ahire, D. Y. Golhar, and M. A. Waller, "Development and validation of TQM implementation constructs," Decision Sciences, vol. 27, no. 1, pp. 23-56, 1996.

[39] J. F. Hair, W. C. Black, B. Babin, R. E. Anderson, and R. L. Tatham, Multivariate Data Analysis, Prentice Hall, New York, NY, USA, 6th edition, 2005. 


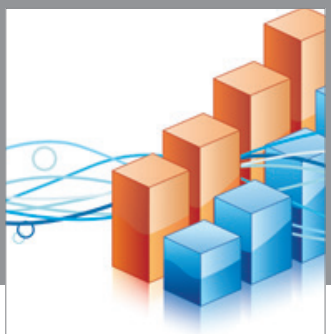

Advances in

Operations Research

vatem alat4



\section{The Scientific} World Journal
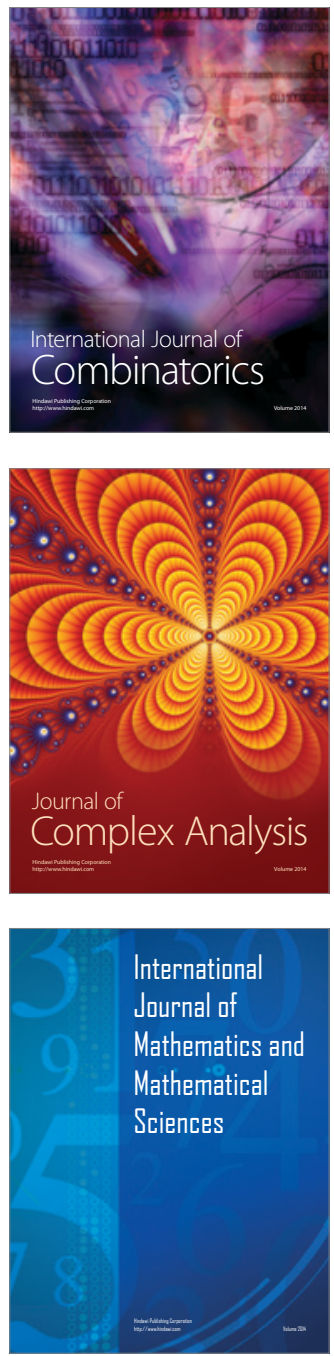
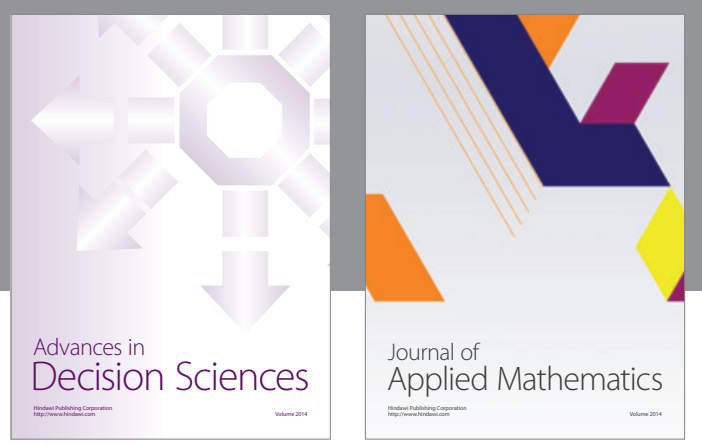

Algebra



\section{Hindawi}

Submit your manuscripts at

http://www.hindawi.com
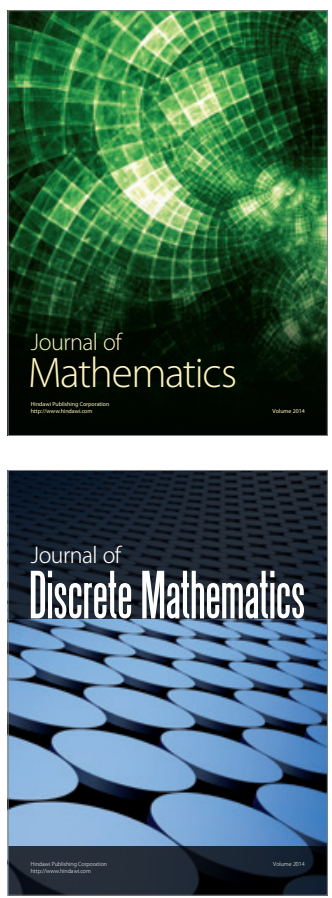

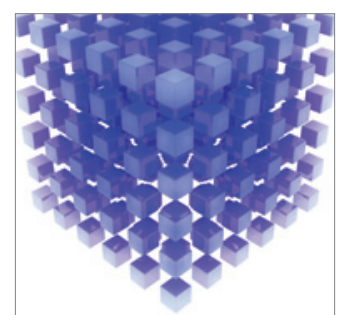

Mathematical Problems in Engineering
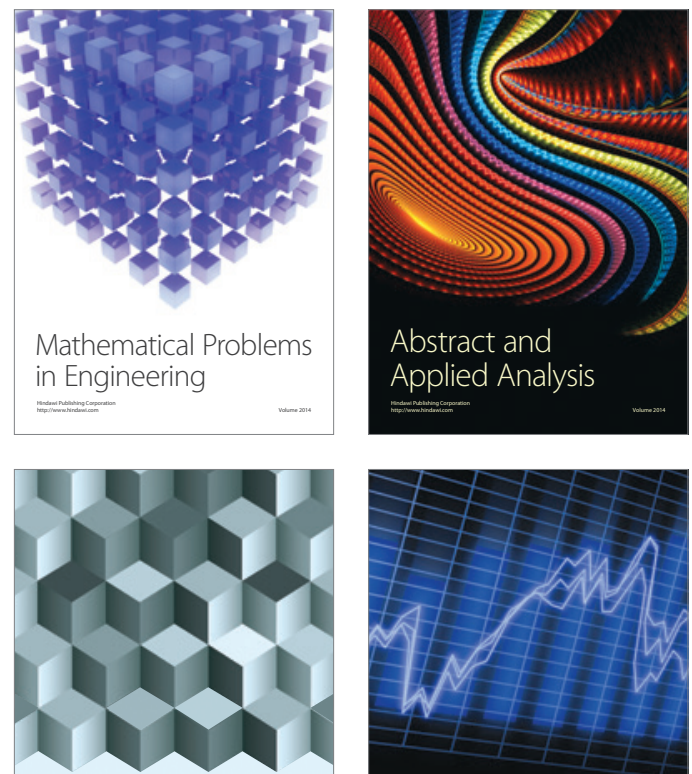

Journal of

Function Spaces



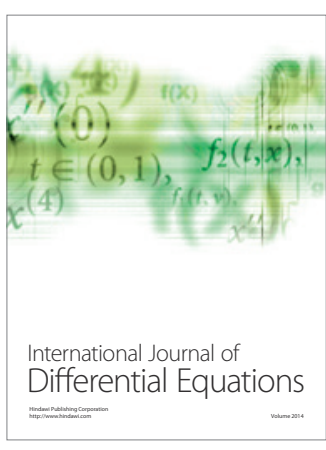
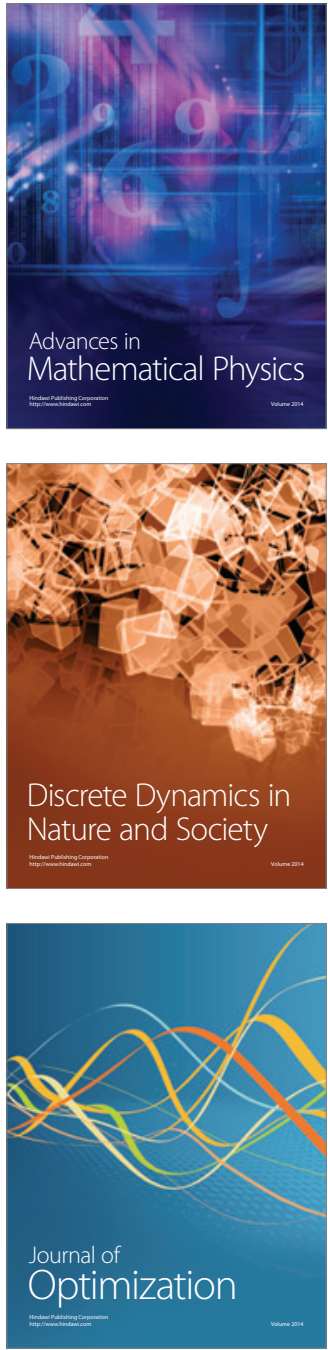